\title{
T-bet expression in CD8+ T cells associated with chronic hepatitis $B$ virus infection
}

\author{
Rongshan Fan', Yinghua Lan', Jiwang Chen², Yanxin Huang ${ }^{1}$, Qin Yan ${ }^{1}$, Lisheng Jiang ${ }^{1}$, Shupeng Song ${ }^{1}$ \\ and Yongguo $\mathrm{Li}^{1^{*}}$
}

\begin{abstract}
Background: The mechanisms leading to virus-specific CD8+ T cell dysfuction in chronic hepatitis B virus (HBV) infection remain to be elucidated. Our study focused on the role of transcription factor T-bet in HBV infection because it is a crucial regulator of $T$ cell immunity.

Methods: We assessed the expression of T-bet along with PD-1, IFN- $\gamma$ and perforin, in HBV-specific CD8+ T cells from resolved acute hepatitis B (rAHB) patients, chronic hepatitis B (CHB) patients, as well as asymptomatic HBV carriers (ASCs). We observed dynamic changes of T-bet, PD-1, IFN- $\gamma$ and perforin in acute stage and recovery stage of acute hepatitis B (AHB).

Results: Comparing with other cohorts, HBV-specific CD8+ T cells from rAHB demonstrated a superior ability in T-bet, IFN- $\gamma$ and perforin expression, but an inferior ability in PD-1 expression. In the CHB group, the level of T-bet has a linear relationship with the level of PD-1, IFN- $\gamma$ and HBV DNA, respectively. A lower expression of T-bet and PD-1 was observed in ASCs when compared with CHB. A higher expression of T-bet, PD-1, IFN-r and perforin was observed in acute stage when compared with the recovery stage of AHB.
\end{abstract}

Conclusions: Our results suggest that expression of T-bet may influence the function of HBV-specific CD8+ T cells and thus can be an attractive target for modulation to improve HBV-specific immunity in CHB.

Keywords: T-bet transcription factor, Hepatitis B virus, CD8 positive T lymphocytes

\section{Background}

Both the quantity and quality of the adaptive antiviral immune response influence the clinical outcome of HBV infection [1]. A multi-specific and vigorous $\mathrm{T}$ cell response is present in acute hepatitis $\mathrm{B}(\mathrm{AHB})$ patients who have successfully cleared HBV infection. However, in chronic HBV infection including $\mathrm{CHB}$ and ASCs, the $\mathrm{T}$ cell immune responses are weak and oligoclonal [2]. $\mathrm{HBV}$-specific CD8+ T cells play important roles in clearance of HBV infection and in the control of HBV replication [3]. A sustained and potent $\mathrm{CD} 8+\mathrm{T}$ cell response to $\mathrm{HBV}$ antigen is associated with resolved acute $\mathrm{HBV}$ infection, but not with chronic HBV infection [4].

Chronic HBV infection acquired perinatally or in early childhood is believed to progress through distinct

\footnotetext{
* Correspondence: liyongguodoctor@163.com

${ }^{1}$ Department of Infectious Diseases, The First Affiliated Hospital of Harbin Medical University, Post Street 23rd, Nangang District, Harbin 150001,

People's Republic of China

Full list of author information is available at the end of the article
}

phases: immune tolerant, immune active and inactive carrier. ASC means a patient is in immune tolerant phase, while $\mathrm{CHB}$ means a patient is in immune active phase [5]. The constant existence of viral antigens intrinsic in chronic infection may lead to loss of function in antigen-specific $\mathrm{T}$ cells, decreased production of interleukin- 2 (IL-2), tumor necrosis factor (TNF), interferon gamma (IFN- $\gamma$ ) and chemotactic factor $\beta$, and gradually impaired proliferation, decreasing cytotoxicity as well as diminishing ability of $\mathrm{T}$ cell survival which eventually result in T cell exhaustion [6].

Immunoregulation is centrally involved in T cell exhaustion. These negative pathways can be grouped into three main categories: cell surface inhibitory receptors (such as PD-1), soluble factors (such as IL-10), and immunoregulatory cell types (such as regulatory T cells). In addition, several specific transcriptional pathways have been implicated in $\mathrm{T}$ cell exhaustion. Particularly, the 
transcription factor T-bet is centrally involved in CD8+ $\mathrm{T}$ cell exhaustion [7].

T-bet, which belongs to the T-box transcription factor family, is encoded by the Tbx 21 gene and expressed in many immune cells, showing an extensive immunoregulatory function [8]. T-bet sustains the effector function of $\mathrm{CD} 8+\mathrm{T}$ cells through various mechanisms, such as regulation of CD8+ T cell proliferation, suppressed expression of inhibitory receptors such as PD-1, and promotion of IFN- $\gamma$ and perforin secretion [9]. Dysfunction of CD8+ $\mathrm{T}$ cells has been found in mice with defective Tbx21 and chronic infection occurred after LCMV infection [10]. Chronic HIV infection leads to decreased T-bet expression in HIV-specific CD8+ T cells $[11,12]$. Moreover, T-bet has been implicated as an anti-tumor regulator and pathogenic factor for autoimmune diseases [13, 14].

Currently, the correlation between the impaired regulation of T-bet and the development of chronic HBV infection has not been established. A study by Kurktschiev $\mathrm{PD}$ et al. assessed the influence of T-bet on CD8 + T cells activity observed during acute and chronic HBV infection [15]. In our study, patients with HBV infection were further divided into three groups: $\mathrm{AHB}, \mathrm{CHB}$ and ASCs. We have determined T-bet expression in these groups and examined its correlation with the clinical outcome. Our observations suggest a central role of Tbet in regulating different immune states of $\mathrm{HBV}$ infection.

\section{Methods}

\section{Research subjects}

From May 2013 to December 2014, patients and controls with positive human leukocyte antigen-A2 (HLAA2) from the Department of Infectious Diseases in the First Affiliated Hospital of Harbin Medical University (Harbin, China) or the Department of Infectious Diseases in the Second Hospital of Daqing (Daqing, China) were recruited for this study. Among these volunteers, there were $9 \mathrm{AHB}$ patients, $18 \mathrm{CHB}$ patients, and 15 ASCs. The patient characteristics are summarized in Table 1.

\section{Diagnostic criteria}

Subjects were selected according to previously described criteria [16] as the following: AHB was defined as acute onset of nonspecific flu-like symptoms and jaundice in previously healthy persons with peak alanine aminotransferase (ALT) elevation 10 times above the upper limit of normal, and was confirmed by concomitant detection of hepatitis B surface antigen (HBsAg), HBV DNA, or anti-hepatitis B core IgM antibody (anti-HBcIgM). rAHB was confirmed by seroconversion of hepatitis B surface antibodies (anti-HBs). CHB was defined by detection of HBV DNA or HBsAg for more than 6 months with ALT fluctuations. ASCs were defined as HBsAg positive, ALT and aspartate aminotransferase (AST) within the normal range for more than 3 visits, and a history of HBV infection. Patients with other possible causes for chronic liver damage, such as alcohol use, drug use, congestive heart failure and autoimmune diseases, and pregnant women were also excluded from this study.

\section{Ethics statement}

The experiments in this study were carried out under the guidance of moral standards described in Declaration of Helsinki and International Ethical Guidelines for Biomedical Research Involving Human Subjects by Council for International Organizations of Medical Sciences (CIOMS), with the approval of ethics committee in First Affiliated Hospital of Harbin Medical University (approval ID: ChiCTR-CCC-14004949). An informed consent was signed by all study subjects.

Table 1 Clinical characteristics of the three patient groups

\begin{tabular}{|c|c|c|c|c|}
\hline & $\mathrm{AHB} n=9$ & $\mathrm{CHB} n=18$ & $\operatorname{ASCs} n=15$ & $P$ values \\
\hline Age (years, mean $\pm S D)$ & $33.67 \pm 5.32$ & $42.45 \pm 4.67$ & $20.22 \pm 3.71$ & $<0.0001$ \\
\hline Gender ( male/female) & $5 / 4$ & $10 / 8$ & $8 / 7$ & \\
\hline $\mathrm{HBsAg}(+/-)$ & $9 / 0$ & $18 / 0$ & $15 / 0$ & \\
\hline $\mathrm{HBsAb}(+/-)$ & $1 / 8$ & $0 / 18$ & $0 / 15$ & \\
\hline HBeAg $(+/-)$ & $3 / 6$ & $11 / 7$ & $15 / 0$ & \\
\hline $\mathrm{HBeAb}(+/-)$ & $8 / 1$ & $7 / 11$ & $0 / 15$ & \\
\hline $\mathrm{HBCAb}(+/-)$ & $9 / 0$ & $18 / 0$ & $15 / 0$ & \\
\hline Median HBV DNA level $\left(\log _{10} \mathrm{IU} / \mathrm{mL}\right)$ & $4.69(2.69-5.55)$ & $5.31(2.26-8.58)$ & $7.99(4.04-8.57)$ & $=0.0012$ \\
\hline $\mathrm{ALT}$ (units/L)mean $\pm \mathrm{SD}$ & $1773.11 \pm 1038.47$ & $523 \pm 775.40$ & $19.43 \pm 5.47$ & $<0.0001$ \\
\hline
\end{tabular}

Abbreviations: $A H B$ acute hepatitis $B, C H B$ chronic hepatitis $B, A S C s$ asymptomatic hepatitis $B$ virus carriers, $H B s A g$ hepatitis $B$ virus surface antigen, $H B s A b H B s A g$ antibody, $H B e A g$ hepatitis $B$ e antigen, $H B e A b \mathrm{HBeAg}$ antibody, HBCAb hepatitis B core antibody, HBV DNA hepatitis B virus DNA, ALT alanine aminotransferase.

$P$ values given as comparison among 3 groups by Kruskal-Wallis test 


\section{Synthetic peptides, pentamers, and cytokines}

Recombinant $\mathrm{HBV}$ core antigen $(\mathrm{HBcAg})$ covering the overall protein sequence of HBV genotype D was purchased from ProSpec (NJ, USA). Human leukocyte antigen (HLA) restricted peptide HBV core antigen 18-27 (FLPSDFFPSV and FLPSDFFPSI, HBV c 18-27) was purchased from Proimmune (Oxford, UK). HBcAg and HBV c 18-27 were used for the in vitro stimulation of HBV-specific CD8+ T cells. HBV c 18-27 was detected by PE-labeled MHC-I restricted pentamers (Proimmune, Oxford, UK). Recombinant human IL-2 (PeproTech, NJ, USA) was used for stimulation experiments.

\section{Monoclonal antibodies for flow cytometry}

FITC anti-human HLA-A2 (BioLegend, San Diego, CA, USA), PE-Cy7 anti-human/mouse T-bet (eBioscience, San Diego, CA, USA), APC anti-Human CD8a (eBioscience, San Diego, CA, USA), FITC anti-human CD279 (PD-1) (BioLegend, San Diego, CA, USA), PerCP anti-CD14 (eBioscience, San Diego, CA, USA), APCeFluor ${ }^{\circ} 780$ anti-CD19 (eBioscience, San Diego, CA, USA) and 7-AAD (BD Biosciences, San Diego, CA, USA) were used for flow cytometry. Isotype control was used for each antibody. The Foxp3/Transcription Factor Staining Buffer Set Kit (eBioscience, San Diego, CA, USA) was used for intracellular staining according to the manufacturer's instructions.

\section{HLA-A2 genotype detection}

Screening for HLA-A2 was performed by staining peripheral blood mononuclear cells (PBMCs) with a FITClabeled mouse anti-HLA-A 2 and isotype control (BD, Biosciences, San Diego, CA, USA).

\section{Isolation of PBMCs}

PBMCs were isolated from fresh heparinized blood using Ficoll-Hypaque density gradient centrifugation and were either analyzed directly or resuspended in medium for stimulation of PBMCs.

\section{PBMC stimulation}

For HBV-specific CD8+ T cells expansion, PBMCs were cultured for 10 days in RPMI 1640 medium containing $2 \mathrm{mM}$ l-glutamine, $1 \mathrm{mM}$ sodium pyruvate, $100 \mathrm{U} / \mathrm{ml}$ of penicillin, $100 \mu \mathrm{g} / \mathrm{ml}$ of streptomycin and $5 \%$ human type AB serum. PBMCs were seeded at a density of $1 \times$ $10^{6} / \mathrm{ml}$ in 24 -well plates, and $1 \mathrm{ml}$ medium was used in each well. In the cytokine-stimulated groups, IL-2 $(20 \mathrm{IU} / \mathrm{ml})$ was added on day 0 . The antigen-stimulated groups received $5 \mu \mathrm{g} / \mathrm{ml}$ of antigen on day 0 and were re-stimulated with the same dose of antigen on day 10. HBcAg ( $5 \mathrm{ug} / \mathrm{ml}$;) and HBV c 18-27 (FLPSDFFPSV, $5 \mathrm{ug} / \mathrm{ml}$; FLPSDFFPSI, $5 \mathrm{ug} / \mathrm{ml}$ ) were used for stimulation. After stimulation, cells were prepared for flow cytometry by cell surface staining and intracellular staining [17].

\section{Cell surface staining and intracellular staining for flow cytometry}

$2-3 \times 10^{6}$ PBMCs were stained with MHC-I pentamers according to the manufacturer's instructions. After staining with viability dyes and antibodies specific for surface markers, cells were fixed with intracellular fixation buffer and permeabilized with permeabilization buffer. After the permeabilization step, cells were stained with intracellular markers. For ex vivo staining, at least 200,000 $\mathrm{PBMCs}$ were collected for pentamer $+\mathrm{CD} 8+\mathrm{T}$ cells as they were low frequency cells. Samples were acquired on a FACSCanto II flow cytometer (BD, Biosciences, San Diego, CA, USA). Data were analyzed with FlowJo 9.6.1 software (Tree Star). Gating strategy excluded monocytes (CD14+), B-lymphocytes (CD19+), and dead cells (7-AAD+) by a dump channel.

\section{Enzyme-linked immunosorbent assay (ELISA)}

PBMCs were cultured for HBV-specific CD8+ T cell expansion with stimulation by HBV antigen and peptides for 10 days. Cells were then seeded into 96-well plates at a density of $1 \times 10^{5}$ cells in $100 \mu \mathrm{l}$ RPMI 1640 medium in each well, and then stimulated again with HBV c 18-27 for $18 \mathrm{~h}$. Subsequently, the cells and supernatant were collected. A human IFN- $\gamma$ embedded ELISA kit (Dakewe Biotech, Beijing, China) and a human perforin embedded ELISA kit (Dakewe Biotech) were used according to the manufacturer's instructions. Data were detected with a microplate reader and analyzed thereafter.

\section{Statistical analysis}

All data were analyzed using Prism 5.0 software (GraphPad, CA, USA). Data were expressed as the median with range or mean \pm SEM. The Kruskal-Wallis Test was performed to test the differences between the three groups, and the difference of every two groups was tested using the Mann-Whitney test (median) or $t$ test (mean). Spearman's rank correlation test was used for correlation analysis. $P$-values of $P<0.05$ were considered significant.

\section{Results}

\section{HBV-specific CD8+ T cell responses}

Cell surface staining of PBMCs after in vitro induction was carried out, and the percentage of HBV-specific CD8+ T cells was analyzed by FACS for patients in the rAHB, CHB or ASC groups respectively. The percentage of $\mathrm{HBV}$-specific CD8+ T cells in the total CD8+ T cells of the rAHB, $\mathrm{CHB}$ and ASC group was $2.04 \%, 1.14 \%$ and $0.46 \%$, respectively $(P<0.0001$ by Kruskal-Wallis test, Fig. 1). 


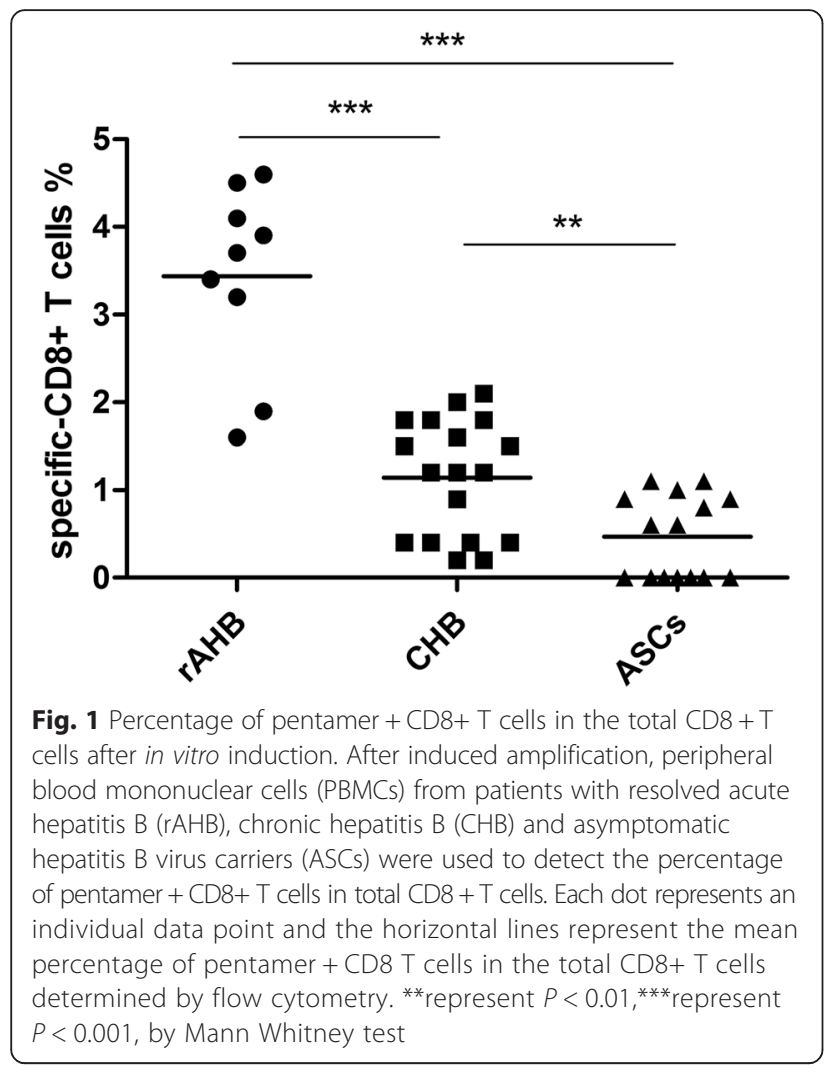

T-bet expression level in HBV-specific CD8+ T cells

The percentage of T-bet + cells in the total CD8+ T cells of the $\mathrm{rAHB}, \mathrm{CHB}$ and ASC groups was $41.21 \%$, $39.94 \%$ and $31.42 \%$, respectively, with no significant difference $(P=0.8619$, by Kruskal-Wallis test, Fig. 2a). As shown in Fig. 2b, the percentage of T-bet + cells in the HBV-specific CD8+ T cells of the $\mathrm{HAHB}, \mathrm{CHB}$, and ASC groups was $78.62 \%, 52.67 \%$ and $10.37 \%$, respectively $(P<0.0001$, by Kruskal-Wallis $H$ test). The percentage in the rAHB group was higher than that in $\mathrm{CHB}$ group $(P<0.01$, by Wilcoxon test), while the latter was higher than that in the ASC group $(P<0.01$, by Wilcoxon test).

\section{PD-1 expression level in HBV-specific CD8+ T cells}

The percentage of PD- $1+$ cells in the total CD8+ T cells of the rAHB, CHB and ASCs was 6.79 \%, 5.64\% and $7.75 \%$, respectively, with no significant difference $(P=0.8099$, by Kruskal-Wallis test, Fig. 3a). The percentage of PD-1+ cells in the HBV-specific CD8+ T cells of the $\mathrm{rAHB}, \mathrm{CHB}$ and ASC groups was $31.51 \%, 50.68 \%$ and $17.44 \%$, respectively, with significant difference $(P=0.0013$, by Kruskal-Wallis test, Fig. $3 \mathrm{~b})$. The percentage in the rAHB group was lower than that in the CHB group $(P<0.01$, by Wilcoxon test). The percentage in the $\mathrm{CHB}$ group was higher than that in the ASC group $(P<0.01$, by Wilcoxon test).
Induced IFN- $\gamma$ and perforin levels in HBV-specific T cells PBMCs isolated from the three groups were induced for 10 days with HBV antigens, followed by a further stimulation with HBV antigens for $18 \mathrm{~h}$. IFN- $\gamma$ and perforin in the supernatant were detected by ELISA. PHA-stimulated $(5 \mathrm{ug} / \mathrm{ml})$ samples were used as positive controls, and samples without antigen stimulation were used as negative controls. Virus antigen stimulation resulted in similar IFN- $\gamma$ and perforin levels compared with that stimulated by PHA. The IFN- $\gamma$ levels in the AHB group were higher than those in the $\mathrm{CHB}$ group $(P<0.0001$, by unpaired $t$ test $)$ and those in the ASC group $(P<0.0001$ by unpaired t test). The IFN$\gamma$ levels in the $\mathrm{CHB}$ group and the ASC group had no significant differences $(P=0.2011$, by unpaired $t$ test). The perforin levels in the rAHB group were higher than those in the CHB group $(P<0.0001$, by unpaired test $)$ and those in the ASC group $(P<0.0001$, by unpaired t test). The perforin levels in the CHB and ASC groups had no significant difference ( $P=0.1842$, by unpaired t test, Fig. 4 ).

\section{Relationships between T-bet, PD-1, IFN- $\gamma$ and HBV DNA in CHB}

To further explore if T-bet can suppress PD-1 expression, promote IFN- $\gamma$ production and eventually affect serum HBV DNA levels, we analyzed the correlation between the percentage of $\mathrm{T}$-bet $+\mathrm{HBV}$ specific $\mathrm{CD} 8+\mathrm{T}$ cells and PD-1+ HBV-specific CD8+ T cells, HBV DNA load or IFN- $\gamma$ level of the $\mathrm{CHB}$ patients. As shown in Fig. 5, the percentage of T-bet $+\mathrm{HBV}$-specific CD8+ T cells showed a significant negative correlation to the percentage of PD-1+ HBV-specific CD8+ T cells ( $r=-0.8638$, $P<0.0001$; Fig. 5a). The percentage of T-bet $+\mathrm{HBV}$-specific $\mathrm{CD} 8+\mathrm{T}$ cells showed a significant negative correlation to viral load of $\mathrm{HBV}(\mathrm{r}=-0.8741, P<0.0001$; Fig. 5b). The percentage of $\mathrm{PD}-1+\mathrm{HBV}$-specific CD8+ $\mathrm{T}$ cells showed a significant positive correlation to viral load of $\operatorname{HBV}(\mathrm{r}=0.8864, P<0.0001$; Fig. $5 \mathrm{c}$ ). The percentage of T-bet + HBV-specific CD8+ T cells showed a significant positive correlation to IFN- $\gamma$ level $(r=0.7193, P=0.0008$; Fig. 5d), The percentage of PD-1+ HBV-specific CD8+ T cells showed a significant negative correlation to IFN- $\gamma$ level ( $\mathrm{r}=-0.7027, P=0.0011$; Fig. 5e)

\section{Dynamic changes of T-bet, PD-1, IFN- $\gamma$ and perforin in AHB}

We further compared the percentage of T-bet + cells and PD-1+ cells in the total HBV-specific CD8+ T cells, as well as their capability for secretion of IFN- $\gamma$ and perforin between the acute stage and recovery stage of the 7 AHB patients. Peripheral blood was collected when the patients had been in hospital for 2 weeks, or had left hospital for 16 weeks, respectively. The cells were induced by antigens and each index was detected after a 10-day in vitro culture. As shown in Fig. 6, along with 


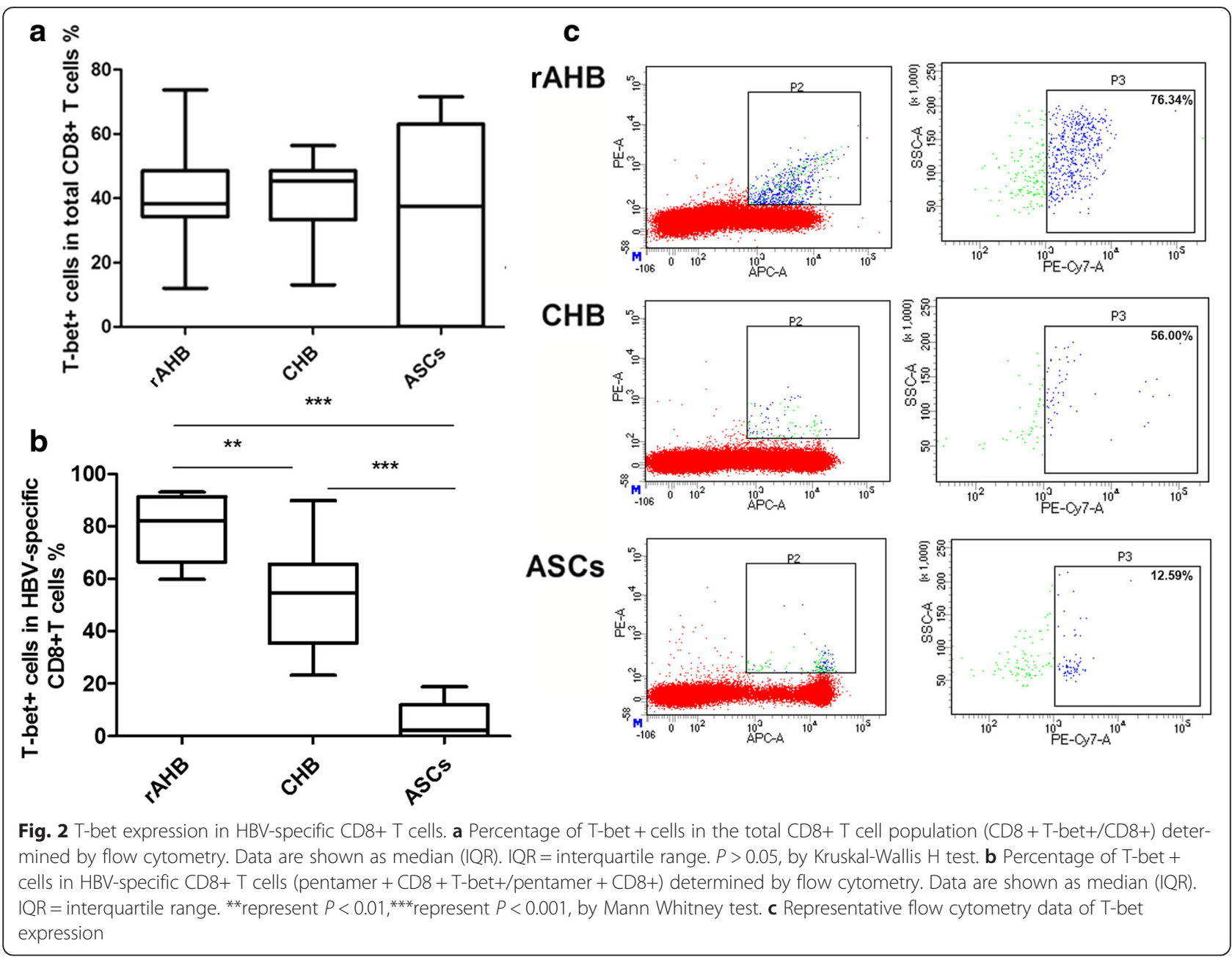

the recovery of disease, expression of T-bet, PD-1, IFN- $\gamma$ and perforin decreased 4 months after hospital discharge accompanied by reduced percentage of HBV-specific CD8+ T cells.

\section{Discussion}

The poor T-bet expression in virus-specific CD8+ T cells may be a central regulation factor for $\mathrm{T}$ cell exhaustion [7]. We compared in vitro amplification of HBV-specific CD8+ T cells isolated from $\mathrm{AHHB}$ and $\mathrm{CHB}$ patients and ASCs, under stimulation by viral antigens. Similar to previous study [4], we found dysfunction and low response of HBV-specific CD8+ T cells in the CHB patients and ASC patients comparing with those of $\mathrm{rAHB}$ patients. The expression of T-bet in the HBV-specific CD8+ T cells of CHB and ASCs were significantly lower than those of rAHB patients. The T-bet expression was lowest in the HBV-specific CD8+ T cells of ASCs. It has been demonstrated that overexpression of T-bet can promote $\mathrm{T}$ cell response, while suppression of T-bet expression can inhibit $\mathrm{T}$ cell response [18]. Our data showed expression of T-bet was in accordance with HBV specific CD8+ T cell response. Similar results concerning T-bet expression were observed in HIV infected patients [11]. Our data suggest that T-bet might regulate the level of the HBV-specific CD8+ T cell response, and low T-bet levels might be an important factor leading to exhaustion of cytotoxic $\mathrm{T}$ cells in chronic hepatitis $\mathrm{B}$. In the CHB group, the level of T-bet had a negative correlation with the level of HBV DNA, suggesting T-bet expression is vital for HBV clearance. The study by Kurktschiev PD et al. compared T-bet expression between AHB and CHB [15]. Our study further showed that the level of T-bet was lower in ASCs than in CHB. We propose that lower expression of T-bet may be a factor of immune tolerance and higher expression of T-bet may trigger a biological process leading to loss of immune tolerance.

The axis of PD- 1 and its ligand is a major inhibitory receptor pathway involved in $\mathrm{CD} 8+\mathrm{T}$ cell exhaustion [7], and PD-1 can be suppressed by T-bet in chronic murine LCMV infection [9]. IL-12 can induce T-bet and 


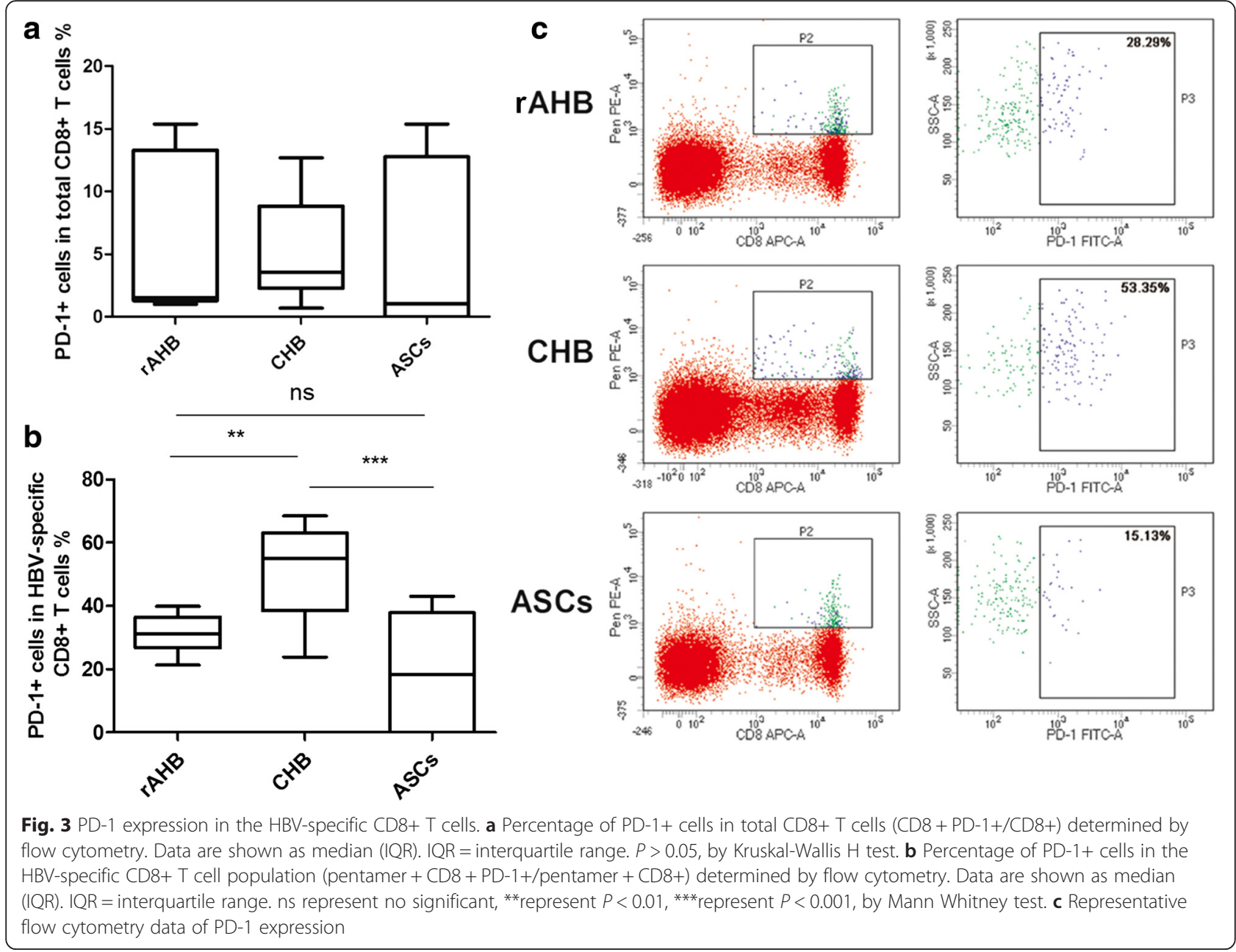

decrease PD-1 expression level in chronic hepatitis B and restore IFN production [19]. In our study, PD-1 expression was higher in the HBV-specific CD8+ T cells of $\mathrm{CHB}$ patients comparing with those of rAHB patients, and a higher PD-1 expression was coexisting with a lower HBV-specific CD8 + T cell response. The PD-1 expression level was positively correlating with the level of
HBV DNA in CHB patients. This suggests that PD-1/PDL1 pathway may inhibit HBV clearance by inhibiting HBVspecific CD8+ T cells. A similar PD-1 expression was observed in HIV infected patients [20]. It was noted that the PD-1 expression was lower in the ASC group than in the $\mathrm{CHB}$ group. One reason is that ASC patients is in immune tolerant phase, and PD-1 expression is lower in immune
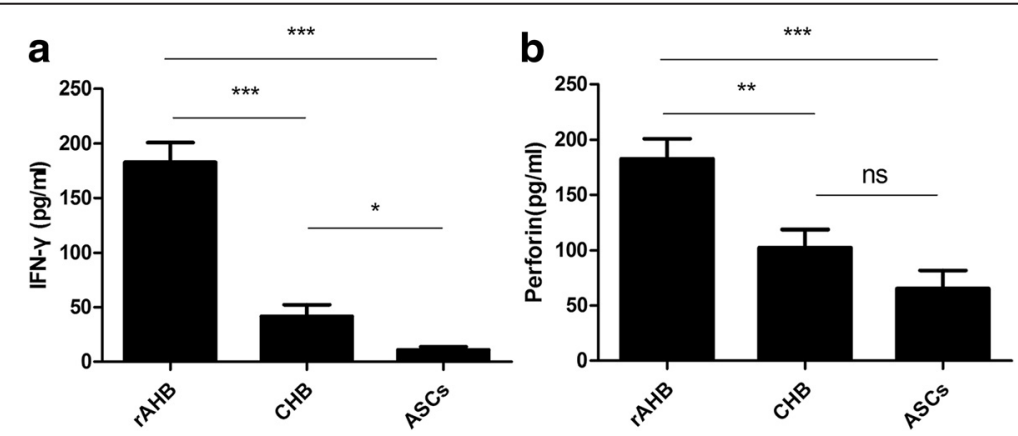

Fig. 4 IFN- $\gamma$ and perforin levels in the HBV-specific CD8+ T cell population. a Mean level of IFN- $\gamma$ produced by HBV-specific T cells. Error bars indicate SEM. b Mean level of Perforin levels produced by HBV-specific T cells. Error bars indicate SEM. *represents $P<0.05$, ${ }^{* *}$ represents $P<0.01$, ***represents $P<0.001$, ns means no significant, by unpaired t test 

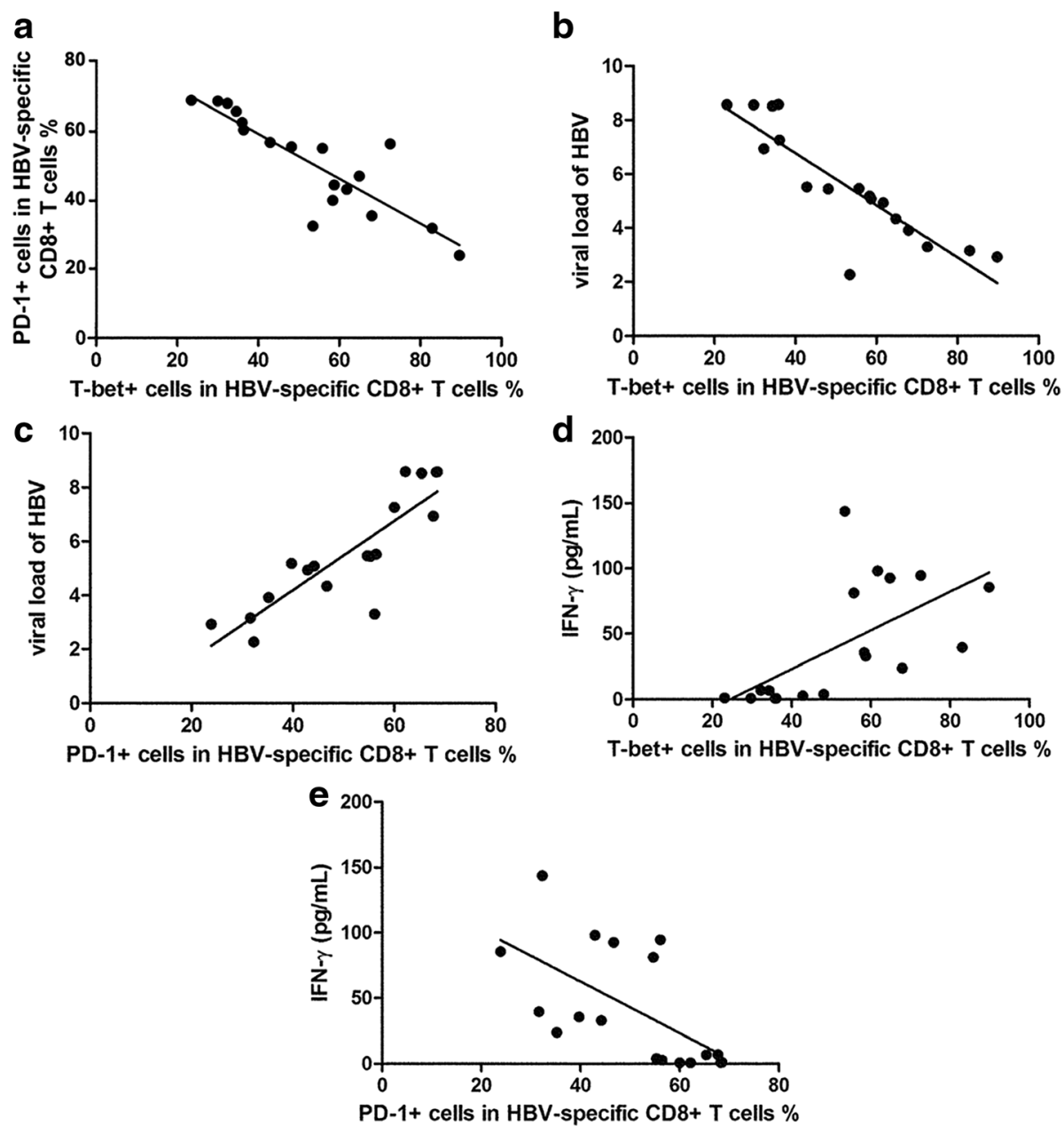

Fig. 5 Correlation between percentage of T-bet + or PD-1+ HBV-specific CD8+ T cells and HBV DNA content or IFN- $\gamma$ level in PBMC from CHB patients. a The percentage of T-bet + cells was negatively related to the percentage of PD- $1+$ cells $(r=-0.8638, p<0.0001)$; $\mathbf{b}$ The percentage of T-bet + cells was negatively related to HBV DNA $(r=-0.8741, p<0.0001)$; $\mathbf{c}$ The percentage of PD-1+ cells was positively related to HBV DNA $(r=0.8864, p<0.0001)$; $\mathbf{d}$ The percentage of T-bet + cells was positively related to IFN- $\gamma$ level $(r=0.7193, p=0.0008)$; e The percentage of PD- $1+$ cells was negatively related to IFN- $\gamma$ level $(r=-0.7027, p=0.0011)$, Spearman rank correlation test was used for data analysis

tolerant phase than in immune active phase [21]. Another reason is that the ASC patients we chose were younger than the CHB patients, and PD-1 expression is lower in the young adult patients than in the older cohort from chronic HBV infected patients [22].

As a 'master regulator' of cell-mediated immunity, Tbet participates in regulation of genes encoding effector molecules in immune cells, such as IFN- $\gamma$, perforin, and granzymes [23]. CD8+ T cells participate in clearance of intracellular viruses upon production of IFN- $\gamma$, and can lyse target cells with perforin and granzymes [24]. We observed a high level expression of IFN- $\gamma$ and perforin in the rAHB group and a low level expression of these genes in the $\mathrm{CHB}$ and ASC groups, with a positive correlation between $\mathrm{T}$-bet and IFN- $\gamma$ production in the $\mathrm{CHB}$ group. These results indicate that low T-bet expression in chronic HBV infection might lead to impaired production of IFN- $\gamma$ and perforin. Because the transcription factor eomesodermin also controls production of IFN- $\gamma$ and peforin in effector CD8 + T cells, further studies of the roles of eomesodermin in chronic HBV infection is necessary [25].

We followed up the AHB patients to determine differences in the acute stage and recovery stage of AHB. Our results showed that both T-bet and PD-1 had higher levels along with IFN- $\gamma$ and perforin in the acute stage than in the recovery stage. A previous study also indicated that at clinical onset of acute HBV infection, PD-1 was significantly up-regulated and subsequently led to the functional suppression of $\mathrm{HBV}$-specific $\mathrm{CD} 8+\mathrm{T}$ cells, and that following disease resolution, HBV-specific effector $\mathrm{CD} 8+\mathrm{T}$ cells developed into memory $\mathrm{T}$ cells. During this period, the dynamic PD-1 decrease was numerically correlated with the reduction of $\mathrm{HBV}$-specific 

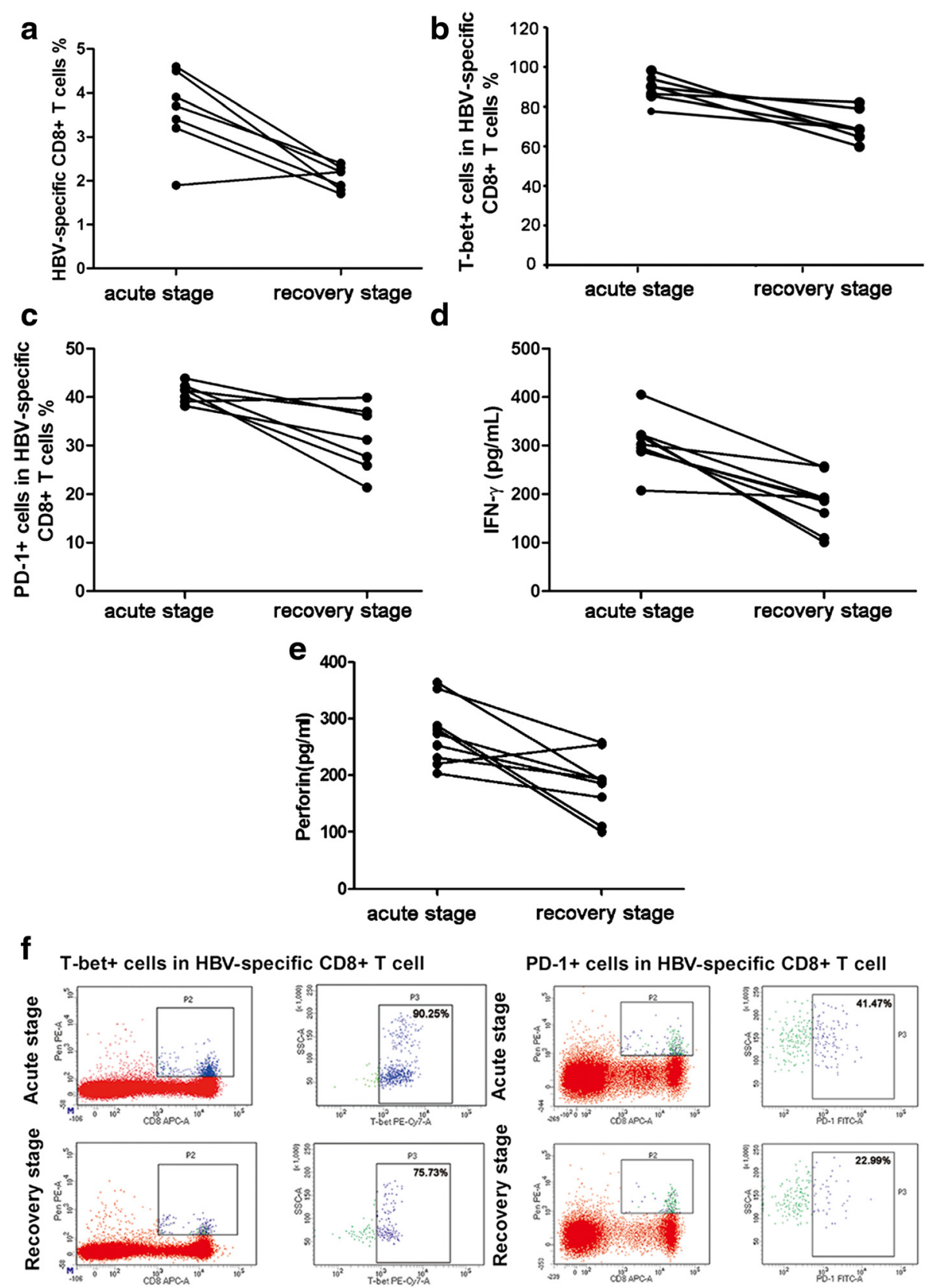

Fig. 6 Changes of HBV-specific CD8+ T cells, T-bet, PD-1, IFN-yand perforin in AHB. a Percentage of HBV-specific CD8+ T cells existed in the acute and recovery stages ( $p=0.0343$, by Wilcoxon signed rank test); $\mathbf{b}$ Level of T-bet in HBV-specific CD8+ T cells in the acute and recovery stages ( $p=0.0156$, by Wilcoxon signed rank test); $\mathbf{c}$ Level of PD-1 in HBV-specific CD8+ T cells in the acute and recovery stages $(P=0.0313$, by Wilcoxon signed rank test); $\mathbf{d}$ Level of IFN- $\gamma$ in HBV-specific CD8+ T cells in the acute and recovery stages ( $P=0.0006$, by paired t test); e Level of perforin in HBV-specific CD8+ T cells in the acute and recovery stages $(P=0.0062$, by paired $t$ test); $\mathbf{f}$ Representative flow cytometry data of T-bet and PD-1 expression in acute stage and recovery stage of AHB

CD8+ T cell frequency [26]. Another study showed that the effect of T-bet on PD-1 expression was modest during acute infection but became greater during chronic infection [9]. We propose that in the acute stage, a high level of T-bet expression can promote amplification of $\mathrm{CD} 8+\mathrm{T}$ cells and result in virus clearance, and that a high level of PD-1 might lead to rapid apoptosis of effector cells. So, the balance between T-bet and PD-1 in the acute phase is critical to virus clearance and pathological damage control.

Concerning the potential mechanism underlying low expression of T-bet in virus specific CD8+ T cells in patients with chronic HBV infection, Smith et al. suggested that during constant infection, antigen presenting cells 
might influence the transcription of transcription factors in virus specific T cells, such as T-bet [27]. EJ Wherry et al. suggested that constant virus infection led to a continuous conversion from T-bet $^{\text {high }}$ progenitor cells to Eomes $^{\text {high }}$ cells in virus specific $\mathrm{CD} 8+\mathrm{T}$ cells, which eventually led to the disappearance of $\mathrm{T}$-bet ${ }^{\text {high }}$ cells [28]. Previous studies have shown that inflammatory signals (e.g., IL-12) not only enhance T-bet expression but may also repress Eomes and thus play a dominant role in regulating memory/effector T-cell potential [29]. The IL-21-induced cytotoxic T cell (CTL) function is T-bet dependent, because $\mathrm{T}$-bet deficiency results in defective IL-21-dependent cytotoxicity in CD8+ T cells in vitro and in vivo [30]. Therefore, it is possible that lack of IL12 or IL-21 results in low T-bet expression in chronic hepatitis B.

\section{Conclusion}

The expression of T-bet is closely related to exhaustion of $\mathrm{T}$ cells in chronic hepatitis $\mathrm{B}$, and T-bet might be a critical factor leading to chronic HBV infection. Further understanding of T-bet function may provide new therapeutic approaches for chronic hepatitis B. We observed different levels of T-bet and PD-1 expression between $\mathrm{CHB}$ and ASC patients, and these may explain the different immune status during chronic HBV infection.

\section{Competing interests}

The authors declare that they have no conflict of interests.

\section{Authors' contributions}

FRS and LYG carried out substantial contribution and designed experiments; FRS, CJW, HYX and YQ carried out experiments; LYH and JLS analyzed experimental results; SSP analyzed data; FRS drafted the manuscript. All authors read and approved the final manuscript.

\section{Acknowledgments}

This study was supported by the grant from the National Key Technologies Research and Development Program of China during the 11th Five-year Plan Period (2008ZX10002-006), and the National Key Technologies Research and Development Program of China during the 12th Five-year Plan Period (2012ZX10002007)

\section{Author details}

'Department of Infectious Diseases, The First Affiliated Hospital of Harbin Medical University, Post Street 23rd, Nangang District, Harbin 150001, People's Republic of China. ${ }^{2}$ Department of Infectious Diseases, The Second Hospital of Daqing City, Daqing City, People's Republic of China.

Received: 9 November 2015 Accepted: 20 January 2016

Published online: 25 January 2016

\section{References}

1. Liaw YF, Chu CM. Hepatitis B virus infection. Lancet. 2009;373:582-92.

2. Guidotti LG, Chisari FV. Immunobiology and pathogenesis of viral hepatitis. Annu Rev Pathol. 2006;1:23-61.

3. Sobao Y, Tomiyama H, Sugi K, Tokunaga M, Ueno T, Saito S, et al. The role of hepatitis B virus-specific memory CD8 T cells in the control of viral replication. J Hepatol. 2002;36:105-15.

4. Boni C, Fisicaro P, Valdatta C, Amadei B, Di Vincenzo P, Giuberti T, et al. Characterization of hepatitis B virus (HBV)-specific T-cell dysfunction in chronic HBV infection. J Virol. 2007;81:4215-25.
5. Della Corte C, Nobili V, Comparcola D, Cainelli F, Vento S. Management of chronic hepatitis B in children: an unresolved issue. J Gastroenterol Hepatol. 2014;29:912-9.

6. Virgin HW, Wherry EJ, Ahmed R. Redefining chronic viral infection. Cell. 2009;138:30-50.

7. Wherry EJ. T cell exhaustion. Nat Immunol. 2011;12:492-9.

8. Lazarevic V, Glimcher LH. T-bet in disease. Nat Immunol. 2011;12:597-606.

9. Kao C, Oestreich KJ, Paley MA, Crawford A, Angelosanto JM, Ali MA, et al. Transcription factor T-bet represses expression of the inhibitory receptor PD-1 and sustains virus-specific CD8+ T cell responses during chronic infection. Nat Immunol. 2011;12:663-71.

10. Hatton RD, Weaver CT. Immunology. T-bet or not T-bet. Science. 2003;302:993-4.

11. Hersperger AR, Martin JN, Shin LY, Sheth PM, Kovacs CM, Cosma GL, et al. Increased HIV-specific CD8+ T-cell cytotoxic potential in HIV elite controllers is associated with T-bet expression. Blood. 2011;117:3799-808.

12. Ribeiro-dos-Santos P, Turnbull EL, Monteiro M, Legrand A, Conrod K, Baalwa $J$, et al. Chronic HIV infection affects the expression of the 2 transcription factors required for CD8 T-cell differentiation into cytolytic effectors. Blood. 2012;119:4928-38.

13. Zhu Y, Ju S, Chen E, Dai S, Li C, Morel P, et al. T-bet and eomesodermin are required for $T$ cell-mediated antitumor immune responses. J Immunol. 2010;185:3174-83.

14. Rangachari M, Mauermann N, Marty RR, Dirnhofer S, Kurrer MO, Komnenovic V, et al. T-bet negatively regulates autoimmune myocarditis by suppressing local production of interleukin 17. J Exp Med. 2006;203:2009-19.

15. Kurktschiev PD, Raziorrouh B, Schraut W, Backmund M, Wachtler M, Wendtner CM, et al. Dysfunctional CD8+ T cells in hepatitis B and C are characterized by a lack of antigen-specific T-bet induction. J Exp Med. 2014;211:2047-59.

16. Webster GJ, Reignat S, Brown D, Ogg GS, Jones L, Seneviratne SL, et al. Longitudinal analysis of CD8+ T cells specific for structural and nonstructural hepatitis B virus proteins in patients with chronic hepatitis B: implications for immunotherapy. J Virol. 2004;78:5707-19.

17. Tsai SL, Lee TH, Chien RN, Liao SK, Lin CL, Kuo GC, et al. A method to increase tetramer staining efficiency of CD8+ T cells with MHC-peptide complexes: therapeutic applications in monitoring cytotoxic T lymphocyte activity during hepatitis B and C treatment. J Immunol Methods. 2004;285:71-87.

18. Joshi NS, Cui W, Chandele A, Lee HK, Urso DR, Hagman J, et al. Inflammation directs memory precursor and short-lived effector CD8(+) T cell fates via the graded expression of T-bet transcription factor. Immunity. 2007;27:281-95.

19. Schurich A, Pallett $L$, Lubowiecki M, Singh HD, Gill US, Kennedy PT, et al. The third signal cytokine IL-12 rescues the anti-viral function of exhausted HBV-specific CD8 T cells. PLoS Pathog. 2013;9:e1003208.

20. Day CL, Kaufmann DE, Kiepiela P, Brown JA, Moodley ES, Reddy S, et al. PD-1 expression on HIV-specific T cells is associated with T-cell exhaustion and disease progression. Nature. 2006;443:350-4.

21. Ren YY, Liu YZ, Ding YP, Song G, Li SH, Wang GQ. Immune characteristics of different immune phases in natural course of chronic HBV infection. Hepatogastroenterology. 2013;60:789-95.

22. Kennedy PT, Sandalova E, Jo J, Gill U, Ushiro-Lumb I, Tan AT, et al. Preserved T-cell function in children and young adults with immune-tolerant chronic hepatitis B. Gastroenterology. 2012;143:637-45.

23. Intlekofer AM, Takemoto N, Wherry EJ, Longworth SA, Northrup JT, Palanivel VR, et al. Effector and memory CD8+ T cell fate coupled by T-bet and eomesodermin. Nat Immunol. 2005;6:1236-44.

24. Sullivan BM, Juedes A, Szabo SJ, von Herrath M, Glimcher LH. Antigendriven effector CD8 T cell function regulated by T-bet. Proc Natl Acad Sci U S A. 2003;100:15818-23.

25. Pearce EL, Mullen AC, Martins GA, Krawczyk CM, Hutchins AS, Zediak VP, et al. Control of effector CD8+ T cell function by the transcription factor Eomesodermin. Science. 2003;302:1041-3.

26. Zhang Z, Jin B, Zhang JY, Xu B, Wang H, Shi M, et al. Dynamic decrease in PD-1 expression correlates with HBV-specific memory CD8 T-cell development in acute self-limited hepatitis B patients. J Hepatol. 2009;50:1163-73.

27. Smith C, Elhassen D, Gras S, Wynn KK, Dasari V, Tellam J, et al. Endogenous antigen presentation impacts on T-box transcription factor expression and functional maturation of CD8+ T cells. Blood. 2012;120:3237-45. 
28. Paley MA, Kroy DC, Odorizzi PM, Johnnidis JB, Dolfi DV, Barnett BE, et al. Progenitor and terminal subsets of CD8+ T cells cooperate to contain chronic viral infection. Science. 2012;338:1220-5.

29. Takemoto N, Intlekofer AM, Northrup JT, Wherry EJ, Reiner SL. Cutting Edge: IL-12 inversely regulates T-bet and eomesodermin expression during pathogeninduced CD8+ T cell differentiation. J Immunol. 2006;177:7515-9.

30. Sutherland AP, Joller N, Michaud M, Liu SM, Kuchroo VK, Grusby MJ. IL-21 promotes CD8+ CTL activity via the transcription factor T-bet. J Immunol. 2013;190:3977-84

Submit your next manuscript to BioMed Central and we will help you at every step:

- We accept pre-submission inquiries

- Our selector tool helps you to find the most relevant journal

- We provide round the clock customer support

- Convenient online submission

- Thorough peer review

- Inclusion in PubMed and all major indexing services

- Maximum visibility for your research

Submit your manuscript at www.biomedcentral.com/submit 